will not need the specialized treatment given in special schools and can be given suitable education in ordinary schools. On the other hand, boarding schools or boarding homes are required for a small minority whose special education needs to extend to their life outside the classroom, for children whose home environment is such that they are unlikely to make good progress unless removed from it, and for those who do not live within reach of a special dayschool. Each child's needs should be carefully assessed and should be kept under regular review.

The provision of extra places in special schools and the increasing interest in the needs of backward children in ordinary schools will require a substantial increase in the number of teachers for the educationally sub-normal. Teachers who wish to specialize in this work can attend one-year courses in the education of handicapped children, which are mainly concerned with backward children. In 1962 there will be 16 of these courses taking 250 teachers in all; in addition, a number of shorter courses is available.

The adjustment from school to working life is more difficult for these children than for those of normal ability but can be made easier by the advice of the youth employment officers in finding suitable jobs and by sympathetic guidance and help whether in the form of further education or informal activities arranged by their former school

\title{
THE BUILDING RESEARCH STATION
}

$\mathrm{T}$ HE open days, July 10-13, held by the Building Research Station, Garston, Watford, Hertfordshire, were primarily for the benefit of the building industry-architects, builders, surveyors and building materials manufacturers-leaving aside research in structural engineering, but much of the work displayed was, as might be expected, of general scientific interest. Indeed, the open days were coupled with the official opening by Sir Harry Melville, secretary of the Department of Scientific and Industrial Research, on July 7, of a new laboratory for physical and chemical research on building materials. The building has been erected by the Ministry of Works (superintending architect, $\mathrm{Mr}$. H. A. Snow; superintending engineer, Mr. M. Woolfson; main contractor, Wilson, Lovatt and Sons, Ltd.) as part of the general building programme for the Station. It replaces more than a dozen war-time huts and brings together in one building all the laboratory research on building materials that the Station carries out. In opening the laboratory, Sir Harry Melville referred to the frequently expressed view that good research results most frequently come from unpromising surroundings and primitive apparatus. "Nothing", he said, "can be further from the truth in these days." He went on to point out that the scope of the work of the Station had broadened enormously since its foundation forty years ago, but that materials research is still basic to the whole of the building industry.

Although, as Sir Harry Melville said, materials research is the oldest part of building research, it has always been prosecuted with the best scientific tools of the day and with the most up-to-date techniques. Thus at present electron microscopy, X-ray analysis, infra-red absorption spectroscopy, differential thermal analysis, high-temperature microscopy and microwaves all find application. The Station has indeed been a pioneer in the use of high-temperature microscopy directed to investigations of silicate minerals, and has developed a rapid and elegant technique for observing under the microscope reactions taking place at temperatures up to $2,400^{\circ} \mathrm{C}$. A similar technique applied in the development of an X-ray camera for use up to $1,850^{\circ} \mathrm{C}$. was also on view.

Micro-waves find application in equipment (now available commercially) designed to investigate the dampness of walls, a technique that is being further developed into a promising method of destroying dry rot by the heating effect of the waves, and radioactive techniques in the measurement of the wear of floorsurfacing materials.
Much of the research into building materials is devoted to a study of their fundamental physical and chemical properties, with the dual aim of providing a background of knowledge against which the durability of materials can be judged and of guiding new developments. Among the examples demonstrated were phase-equilibrium investigations on multicomponent aqueous systems designed to increase understanding of the slow chemical reactions that materials undergo in use, and of the distribution of pore-size which has a close bearing on their resistance to frost. Laboratory abrasion tests for flooring materials have been notoriously unreliable, but following an investigation of the forces applied by the foot to the floor a new type of testing device was demonstrated that reproduces these forces.

New forms of construction make new demands on materials and throw up their own problems. Many curtain walling systems rely for their satisfactory performance on mastic materials for jointing. Thermal movements may be comparatively large and may make heavy demands on the mastic. Here the work of the Station has been mainly directed towards the assessment of the properties needed and the development of tests that can be used to evaluate the performance of jointing and caulking materials. The tests demonstrated dealt with rates of movement, stiffening with time, adhesion and load-bearing.

One of the great strengths of the Station is its ability to tackle most-if not all-aspects of problems involved in the development of new materials or processes. This is illustrated by its work on the perforated brick, the manufacture of which was demonstrated during the open days in the pilot-scale laboratory equipped with standard brick-making machinery. Not only has the Station been able to study the development of the design of the briek from the point of view of manufacture and æsthetic acceptability, but also it has been able to study strength, thermal properties, laying methods, rain resistance, and costs.

Visitors were able to see demonstrated the work of the Station on the packaging of building materials and the various units of mechanical plant developed for their handling; methods for fixing and joining plasterboard linings for house interiors, developed so as to remove as much of the wet process from building as possible; and the production of lightweight aggregate from pulverized fuel ash.

Of much current interest is the work on heating, as, for example, of flats, employing an electrical analogue, and of heat transmission through walls and roofs. 
Equally topical is the survey being carried out of noise in London. One of the recording vans was on view, as was the main mobile acoustics laboratory, admirably equipped for almost any acoustical measurement and largely used for the measurement of sound transmission in buildings and for investigations into the laws governing the propagation of sound through the atmosphere.

The use of models finds considerable application in studies of the lighting of buildings, for, when suitably designed, they provide a ready means of obtaining both a factual and a subjective judgment of proposed schemes. The Station is active in establishing the principles on which permanent artificial lighting can be used to supplement day-lighting and thus give a new freedom to architectural planning. Closely associated with lighting is the use of colour in buildings: the one can modify considerably the effectiveness of the other. The range of colours for paint established as B.S. 2660 is now widely accepted, and the Station is engaged in trying to get the principles underlying the paint colours applied to building components such as tiles, linoleum, and plastics.
Allied to the physical investigations were the more subjective studies on the needs of users, illustrated by work on the design of drawing offices and of dwellings for old people.

Another use of three-dimensional models is found in the design of engineering services, and an exhibit showed ways in which they can help to resolve problems in the design of hospitals.

The economic aspects of building design and construction formed another exhibit on a topic of much importance. Here were shown investigations on the influence of the design of flats on their cost, the assessment of the comparative costs of different forms of urban development, and the programming of the sequence of work on building sites.

Altogether, there was much for the main target of the open days-architects and builders-to ponder over. The value of the open days for scientists is perhaps best exemplified by the director of a research organization in an entirely different industry, who went away having seen three pieces of work of immediate application in his own field. Some 3,500 visitors attended.

\title{
A NEW 'WEDGE' TYPE INSTABILITY OBSERVED IN A 'THETA' PINCH
}

\author{
By J. K. WRIGHT, R. ID. MEDFORD, J. D. HERBERT and R. C. POTTINGER \\ Atomic Weapons Research Establishment, Foulness, Southend-on-Sea
}

$\mathrm{R}$ ECENT experiments by Niblett and Green ${ }^{1}$ have shown that flutes are developed on the outer surface of a plasma produced by a theta pinch and these are interpreted as magnetohydrodynamic Rayleigh-Taylor instabilities produced by the acceleration of the interface separating the driving magnetic field and the plasma. Josephson has recently reported another experiment in which he investigated a possible mechanism for neutron production in a theta pinch with reversed trapped magnetic field ${ }^{2}$. Niblett has said (private communication) that in his experiments with Green they made detailed magnetic probe measurements and these showed that in their experiment parallel trapped field was obtained on the second half-cycle. In both experiments high-speed camera shots were taken of the end view of the plasma during the second half-cycle of the discharge.

We have been studying similar phenomena in theta pinches but have made our observations during the first half-cycle of the discharge. The theta piece used was $7.5 \mathrm{~cm}$. long, $3.4 \mathrm{~cm}$. internal diameter and this was wound around the middle of a quartz discharge tube $22 \mathrm{~cm}$. long, $3.0 \mathrm{~cm}$. diameter filled with deuterium gas at pressures of the order of $1 \mathrm{~mm}$. of mercury. Our condenser bank had a capacity of $40 \mu \mathrm{F}$. and was charged to a voltage of $10 \mathrm{kV}$. An explosive type switch discharged the bank through the theta piece. The parameters of the experiment were such that we obtained ${ }^{3}$ a cylindrically converging shock wave on the first half-cycle with trapped magnetic field parallel to the driving field.

Photographs of this discharge have shown an interesting new phenomenon; during the first halfcycle of the discharge we see bright radial 'wedges' with less luminous plasma filling their interstices. Even with radial wedges present it appears that there is still magnetic field trapped by the imploding plasma. About the time of maximum compression it forces its way out of the centre by pushing the plasma in the interstices out towards the wall of the discharge tube, thereby forming flutes which appear to have trapped magnetic field inside them. These outgoing flutes grow into a fascinating octopus pattern similar to that observed by other workers and associated with a rotation of the whole plasma. In our experiment the flutes grow in amplitude following a curved line giving an impression of rotation.

The number of wedges seems to be determined by the irregularities in the system since it can be varied by deliberately introducing irregularities in the external conductors. Figs. 1, 2 and 3 show high-speed framing camera records (about 8 frames per usec.) of the theta pinch on the first half-cycle of the discharge. Figs. 1 and 2 are of theta pinches fired in the Prize 4 apparatus (Fig. 8), where it will be noticed that there are 16 wedges, that is, half the number of wires in the return conductor normally used for the $Z$ pre-ionizer. Fig. 3 is taken with the return conductor removed and the theta piece wound directly on to the discharge tube, and shows that the wedges are randomly spaced and fewer in number; Fig. $\mathbf{3}$ is particularly interesting because it shows the trapped magnetic field apparently pushing its way out of the plasma through the three gaps where the plasma luminosity is least. The resulting outgoing flutes are also seen to grow as a result of the pressure exerted by the trapped magnetic field. A similar effect is also seen in Figs. 1 and 2. The field is observed to be trapped inside the largest flute until the fourth camera frame of Fig. 2, that is about $\frac{1}{2}$ usec. after the first wedges become visible. In order for the diffusion time to be about $\frac{1}{2} \mu$ sec., the electron temperature must be of the order of $5 \times 10^{5}{ }^{\circ} \mathrm{K}$. 